\title{
JNPH
}

Volume 6 No. 1 (April 2018)

(C) The Author(s) 2018

\section{FAKTOR-FAKTOR YANG BERHUBUNGAN DENGAN KEJADIAN ARTHRITIS RHEUMOTOID PADA LANSIA DEWASA MUDA DI WILAYAH KERJA PUSKESMAS RATU AGUNG KOTA BENGKULU}

\section{FACTORS RELATED TO THE OCCURRENCE OF ARTHRITIS RHEUMOTOID ON YOUNG ADULT ELDERLY AT RATU AGUNG HEALTH CENTER IN BENGKULU}

\author{
JONRI HALIZAN \\ UPTD PUSKESMAS PERAWATAN RATU AGUNG KOTA BENGKULU \\ JLN. WR SUPRATMAN NO 22 KELURAHAN PEMATANG GUBERNUR \\ KOTA BENGKULU. 38125 \\ Email: Jonrihalizan@yahoo.co.id/085832055713
}

\begin{abstract}
ABSTRAK
Arthritis RheumotoidCases di Kota Bengkulu pada tahun 2016 yang penderita arthritis menempati semua 5 tingkat mirip dengan Athritis Rheumotoid dengan 7.889 jiwa. Penelitian ini bertujuan untuk mengetahui faktor-faktor yang berhubungan dengan terjadinya Arthritis Rheumotoid di Puskesmas Ratu Agung di kota. Sampel penelitian ini diambil dengan menggunakan accidental sampling, 69 lansia dewasa muda mengunjungi puskesmas. Data dikumpulkan melalui teknik wawancara langsung menggunakan kuesioner. Analisis data dilakukan menggunakan analisis Univariat dan Bivariat dengan uji chi-square pada $\alpha 5 \%$. Hasil penelitian menunjukkan bahwa sebagian besar pengetahuan lansia $49(71,0 \%)$ cukup, mayoritas lansia 38 orang $(55,0 \%)$ adalah perempuan., dan hampir setengah dari lansia $30(43,4 \%)$ memiliki aktivitas sedang, sebagian besar yang tidak secara genetik oleh 37 lansia $(54,0 \%)$. Sebagian besar lansia dewasa muda dari 39 lansia (56,5\%), hampir setengah dari lansia yang tidak memiliki Arthrtitis Rheumotoid 30 orang lanjut usia (43,5\%). Dari hasil chi-square $\mathrm{p}=$ $0,017,0,031,0,017,0,002$, dan 0,002. Tidak menunjukkan hubungan antara pengetahuan, jenis kelamin, aktivitas, kejadian genetik pada lansia dengan Arthritis Rheumotoid di Puskesmas Ratu Agung di kota. Puskesmas diharapkan meningkat untuk memberikan informasi lebih lanjut tentang Arthritis Rheumotoid dalam meningkatkan status kesehatan lansia muda orang dewasa.

Kata kunci: Pengetahuan, Jenis Kelamin, Kegiatan, Genetik
\end{abstract}

\begin{abstract}
Arthritis RheumotoidCases in Bengkulu City in 2016 that arthritis sufferers occupy all 5 levels similar to Athritis Rheumotoid with 7.889 inhabitants. This study aimed to determine the factors associated with the occurrence of Arthritis Rheumotoid at Ratu Agung Health Center in the city.Thesamples of this study were taken by using an accidental sampling, 69 young adult elderly visiting the health center. The data were collected through direct interview techniques using a questionnaire. The data analysis was done using Univariate and Bivariate analysis with chi-square test at $\alpha 5 \%$. The results showed that most of the elderly knowledge $49(71.0 \%)$ were sufficient, the majority of the elderly 38 people $(55.0 \%)$ were female, and almost half of the elderly $30(43.4 \%)$ had medium activity, mostly that no genetically by 37 elderly (54.0\%).Most
\end{abstract}


elderly young adults of 39 elderly (56.5\%), almost half of the elderly who did not have Arthrtitis Rheumotoid 30 elderly people (43.5\%). From the results of the chi-square $p=0.017$, $0.031,0.017,0.002$, and 0.002. Showed no relationship between knowledge, sex, activity, genetic events on the elderly with Arthritis Rheumotoid at Ratu Agung Health Center in the city.The health center is expected to increase to provide more information about Arthritis Rheumotoid in improving the health status of the elderly young adults.

Keywords: Knowledge, Gender, Activities, Genetic

\section{PENDAHULUAN}

Indonesia Sehat2025 mempunyai misi antara lain memelihara dan meningkatkan pelayanan kesehatan individu, keluarga dan masyarakat yang bermutu, merata dan terjangkau. hal ini sesuai dengan paradigma sehat berdasarkan sistem pelayanan promotif, preventif, kuratif dan rehabilitatif yang harus di laksanakan secara menyeluruh terpadu dan berkesinambungan, sehingga masyarakat memiliki derajat kesehatan optimal. (Depkes RI, 2009).

Penderita Athritis Rheumotoid yang berumur lebih dari 45 tahun pada tahun 2012 sebanyak 809 orang penderita, sedangkan pada tahun 2013 sebanyak 898 orang dan pada tahun 2014 mengalami peningkatan yang tinggi yaitu sebanyak 1.070 orang penderita (Dinkes Kota Bengkulu, 2016).Hal ini berarti bahwa jumlah penderita Athritis Rheumotoid di Puskesmas Ratu Agung Kota Bengkulu mengalami peningkatan dari tahun ke tahun. Dari latar belakang di atas maka penelitian tertarik untuk melakukan peneltian tentang faktor-faktor yang berhubungan dengan kejadian Arthritis Rheumotoid pada lansia dewasa muda di wilayah kerja Puskesmas Ratu Agung Kota Bengkulu.

\section{BAHAN DAN METODE}

Tehnik pengumpulan data yang digunakan dalam penelitian ini adalah dengan menggunakan data primer dan data sekunder. Data primer adalah data yang di kumpulkan mlalui penyebaran kuisioner langsung pada responden di Puskesmas Ratu Agung Bengkulu. Sedangkan data sekuder adalah data yang diperoleh dari laporan tahunan dan buku register poli umum Puskesmas Ratu
Agung Bengkulu.

\section{HASIL}

Puskesmas Ratu Agung merupakan Puskesmas Non Perawatan yang berada di jalan Jeruk No. 01 Perumnas Ratu Agung Kelurahan Lingkar Timur, Kecamatan Singaran Pati Kota Bengkulu, dengan luas wilayah $\pm 360 \mathrm{Ha}\left(3,60 \mathrm{Km}^{2}\right)$, jumlah penduduk , 17.379 jiwa, 6.106 kk.Puskesmas Ratu Agung di dukung oleh 43 (Empat puluh tiga) tenaga yang terdiri dari 3 orang dokter umum, 1 orang dokter gigi, 2 orang S1 umum, 8 orang S1 Kesehatan, 4 orang D3 Keperawatan, 3 orang perawat/SPK, 2 orang perawat gigi DI/DIII, 4 orang DI/DIII Kebidanan, 1 orang AKL, 1 orang SMAK, 2 orang SMF, 1 orang pekarya kesehatan dan 1 orang AAK.

Data yang telah di peroleh dari penelitian kemudian di kelompokkan dan ditabulasi sesuai dengan keperluan penelitian. Selanjutnya peneliti melakukan pengolahan data dan analisis data. Hasil penelitian di sajikan dalam anallisis Univariat dari setiap variabel independen dan dependen. Penyajian dilanjutkan dengan hasil analisis Bivariat yang bertujuan untuk mengetahui hubungan antara variable independen dengan variable dependen dengan hasil penelitian sebagai berikut :

Tabel 1 Distribusi Frekuensi Pengetahuan, Jenis Kelamin, Aktivitas, Genetik dan kejadian Athritis Rheumotoid di Wilayah Kerja Puskesmas Ratu Agung Kota Bengkulu 


\begin{tabular}{|c|c|c|c|}
\hline No. & Variabel & $\mathrm{F}$ & $\begin{array}{c}\text { Persentase } \\
(\%) \\
\end{array}$ \\
\hline 1 & $\begin{array}{c}\text { Pengetahuan } \\
\text { a.Kurang } \\
\text { b.Cukup } \\
\text { c.Baik } \\
\end{array}$ & $\begin{array}{c}8 \\
49 \\
12 \\
\end{array}$ & $\begin{array}{l}11,6 \% \\
71,0 \% \\
17,4 \% \\
\end{array}$ \\
\hline & Jumlah & 69 & $100 \%$ \\
\hline 2 & $\begin{array}{c}\text { JenisKelamin } \\
\text { a.Laki-laki } \\
\text { b.Perempuan }\end{array}$ & $\begin{array}{l}31 \\
38 \\
\end{array}$ & $\begin{array}{l}45,0 \% \\
55,0 \% \\
\end{array}$ \\
\hline & Jumlah & 69 & $100 \%$ \\
\hline 3 & $\begin{array}{l}\text { Aktivitas } \\
\text { a.Tinggi } \\
\text { b. Sedang } \\
\text { c.Rendah }\end{array}$ & $\begin{array}{l}13 \\
30 \\
26 \\
\end{array}$ & $\begin{array}{l}19,0 \% \\
43,4 \% \\
37,6 \% \\
\end{array}$ \\
\hline & Jumlah & 69 & $100 \%$ \\
\hline 4 & $\begin{array}{c}\text { Genetik } \\
\text { a.Ya } \\
\text { b.Tidak }\end{array}$ & $\begin{array}{l}32 \\
37 \\
\end{array}$ & $\begin{array}{l}46,0 \% \\
54,0 \% \\
\end{array}$ \\
\hline & Jumlah & 69 & $100 \%$ \\
\hline 5 & $\begin{array}{c}\text { Kejadian Athritis } \\
\text { Rheumotoid } \\
\text { a.Athritis Rheumotoid } \\
\text { b. Tidak Athritis } \\
\text { Rheumotoid }\end{array}$ & $\begin{array}{l}39 \\
30\end{array}$ & $\begin{array}{l}56,5 \% \\
43,5 \%\end{array}$ \\
\hline & Jumlah & 69 & $100 \%$ \\
\hline
\end{tabular}

Berdasarkan tabel 1 diatas dapat dikategorikan sebagian besar responden $(71,0 \%)$ dengan tingkat pengetahuan cukup.Dari data diatas dapat disimpulkan bahwa dari 69 responden, sebagian besar dari responden $(55,0 \%)$ dengan jenis kelamin perempuan. Dari data diatas dapat disimpulkan bahwa dari 69 responden, 30 responden $(43,4 \%)$ hampir sebagian dari responden dengan aktivitas sedang.Dari data diatas maka dapat disimpulkan bahwa dari 69 lansia dewasa muda yang tidak mengalami penyakit genetik terdapat $(54,0 \%)$. Dari data diatas dapat disimpulkan bahwa dari 69 responden, sebagian besar dari responden yaitu 39 lansia $(56,5 \%)$.

Tabel 2. Distribusi Frekuensi Responden Berdasarkan Tingkat Pengetahuan Pada Dewasa Muda Dengan Kejadian Arthritis Rheumotoid Di Wilayah Kerja Puskesmas Ratu Agung Kota Bengkulu

\begin{tabular}{|c|c|c|c|c|c|c|c|c|}
\hline \multirow{3}{*}{\multicolumn{2}{|c|}{$\begin{array}{c}\text { No. Pengetahu } \\
\text { an }\end{array}$}} & \multicolumn{4}{|c|}{$\begin{array}{c}\text { Kejadian Arthritis } \\
\text { Rheumotoid }\end{array}$} & \multicolumn{2}{|c|}{ Total } & \multirow{3}{*}{$\begin{array}{c}\text { Nilai } \\
p\end{array}$} \\
\hline & & \multicolumn{2}{|c|}{ Ya } & \multicolumn{2}{|c|}{ Tidak } & \multirow[t]{2}{*}{$\mathrm{F}$} & \multirow[t]{2}{*}{$\%$} & \\
\hline & & $\mathrm{N}$ & $\%$ & $\mathrm{~N}$ & $\%$ & & & \\
\hline 1 & Baik & 5 & 62,5 & 3 & 37,5 & 8 & $100 \%$ & \multirow{4}{*}{0,017} \\
\hline 2 & Cukup & 29 & 59,0 & 20 & 41,0 & 49 & $100 \%$ & \\
\hline 3 & Kurang & 5 & 42,0 & 7 & 58,0 & 12 & $100 \%$ & \\
\hline & umlah & 39 & 56,5 & 30 & 43,5 & 69 & $100 \%$ & \\
\hline
\end{tabular}

Berdasarkan tabel 2 diatas, diketahui dari 69 responden yang memiliki pengetahuan baik terdapat 5 lansia dewasa muda $(62,5 \%)$ yang mengalami kejadian Arthritis Rheumotoid, sedangkan 20 lansia dewasa muda $(41,0 \%)$ yang tidak mengalami kejadian Arthritis Rheumotoid yang memiliki pengetahuan cukup. Hasil uji statistik dengan menggunakan Chi Square, didapat nilai $p$ value 0,017 yang berarti lebih kecil dari $\alpha$ $(0,05)$ maka Ho ditolak dan Ha diterima, berarti ada hubungan yang bermakna antara pengetahuan dengan Kejadian Arthritis Rheumotoid.

Tabel 3. Distribusi Frekuensi Responden Berdasarkan Jenis Kelamin Dengan Kejadian Arthritis Rheumotoid Di Wilayah Kerja Puskesmas Ratu Agung Kota Bengkulu

\begin{tabular}{|c|c|c|c|c|c|c|c|c|}
\hline \multirow[t]{3}{*}{ No. } & \multirow[t]{3}{*}{ JenisKelamin } & \multicolumn{4}{|c|}{$\begin{array}{c}\text { Kejadian } \\
\text { Arthritis } \\
\text { Rheumotoid }\end{array}$} & \multicolumn{2}{|c|}{ Total } & \multirow[t]{3}{*}{$\begin{array}{c}\text { Nilai } \\
-p\end{array}$} \\
\hline & & \multicolumn{2}{|r|}{ Ya } & \multicolumn{2}{|c|}{ Tidak } & \multirow[t]{2}{*}{$\mathrm{F}$} & \multirow[t]{2}{*}{$\%$} & \\
\hline & & $\mathrm{N}$ & $\%$ & $\mathrm{~N}$ & $\%$ & & & \\
\hline 1 & Laki-laki & 21 & 68,0 & 10 & 32,0 & 31 & $100 \%$ & \\
\hline \multirow[t]{2}{*}{2} & Perempuan & 18 & 47,4 & 20 & 52,6 & 38 & $\overline{100 \%}$ & 0,031 \\
\hline & Jumlah & 39 & 56,5 & 30 & 43,5 & 69 & $100 \%$ & \\
\hline
\end{tabular}

Berdasarkan tabel 3 diatas, diketahui dari 69 Lansia Dewasa Muda yang berjenis kelamin laki-laki terdapat 21 lansia dewasa muda $(68,0 \%)$ yang mengalami kejadian Arthritis Rheumotoid, sedangkan 38 lansia dewasa muda dengan jenis kelamin perempuan terdapat 20 lansia dewasa muda $(52,6 \%)$ yang tidak mengalami kejadian Arthritis Rheumotoid. Hasil uji statistik dengan menggunakan uji Chi Square, didapat 
nilai p-value 0,031 yang berarti lebih kecil dari $\alpha(0,05)$ maka Ho ditolak dan $\mathrm{Ha}$ diterima, berarti ada hubungan yang bermakna antara jenis kelamin dengan Kejadian Arthritis Rheumotoid.

Tabel 4. Distribusi Frekuensi Responden Berdasarkan Aktivitas Dengan Kejadian Arthritis Rheumotoid Di Wilayah Kerja Puskesmas Ratu Agung Kota Bengkulu

\begin{tabular}{|c|c|c|c|c|c|c|c|c|}
\hline \multirow{3}{*}{ No. } & \multirow{3}{*}{ Aktivitas } & \multicolumn{4}{|c|}{$\begin{array}{c}\text { Kejadian Arthritis } \\
\text { Rheumotoid }\end{array}$} & \multicolumn{2}{|c|}{ Total } & \multirow{3}{*}{ Nilai $p$} \\
\hline & & \multicolumn{2}{|c|}{ Ya } & \multicolumn{2}{|c|}{ Tidak } & \multirow{2}{*}{$\mathrm{F}$} & \multirow{2}{*}{$\%$} & \\
\hline & & $\mathrm{N}$ & $\%$ & $\mathrm{~N}$ & $\%$ & & & \\
\hline 1 & Tinggi & 7 & 54,0 & 6 & 46,0 & 13 & $100 \%$ & \\
\hline 2 & Sedang & 28 & 93,3 & 2 & 6,70 & 30 & $100 \%$ & \\
\hline 3 & Rendah & 4 & 15,0 & 22 & 85,0 & 26 & $100 \%$ & 0,017 \\
\hline & Jumlah & 39 & 56,5 & 30 & 43,5 & 69 & $100 \%$ & \\
\hline
\end{tabular}

Berdasarkan tabel 4 diatas, diketahui dari 13 lansia dewasa muda yang melakukan aktivitas tinggi terdapat $(54,0 \%)$ yang mengalami kejadian Athritis Rheumotoid sedangkan dari 26 lansia dewasa muda yang melakukan aktivitas rendah terdapat $(85,0 \%)$ yang tidak mengalami kejadian Athritis Rheumotoid. Hasil statistik dengan menggunakan Uji Chi Square, didapat nilai $p$ value 0,017 yang berarti lebih kecil dari $\alpha$ $(0,05)$ maka Ho ditolak dan Ha diterima, berarti ada hubungan yang bermakna antara aktivitas dengan kejadian Athritis Rheumotoid

Tabel 5. Distribusi Frekuensi Responden Berdasarkan Genetik Dengan Kejadian Arthritis Rheumotoid Di Wilayah Kerja Puskesmas Ratu Agung Kota Bengkulu

\begin{tabular}{|c|c|c|c|c|c|c|c|c|}
\hline \multirow[t]{3}{*}{ No. } & \multirow[t]{3}{*}{ Genetik } & \multicolumn{4}{|c|}{$\begin{array}{c}\text { Kejadian Arthritis } \\
\text { Rheumotoid } \\
\end{array}$} & \multicolumn{2}{|c|}{ Total } & \multirow[t]{3}{*}{ Nilai $p$} \\
\hline & & \multicolumn{2}{|c|}{ Ya } & \multicolumn{2}{|c|}{ Tidak } & \multirow[t]{2}{*}{$\mathrm{F}$} & \multirow[t]{2}{*}{$\%$} & \\
\hline & & $\mathrm{N}$ & $\%$ & $\mathrm{~N}$ & $\%$ & & & \\
\hline 1 & Ya & 12 & 37,5 & 20 & 62,5 & 32 & $100 \%$ & \\
\hline 2 & Tidak & 20 & 54,0 & 17 & 46,0 & 37 & $100 \%$ & 0,002 \\
\hline & umlah & 39 & 56,5 & 30 & 43,5 & 69 & $100 \%$ & \\
\hline
\end{tabular}

Berdasarkan tabel 5 diatas, diketahui dari 32 lansia dewasa muda yang mengalami penyakit genetik terdapat $(37,5 \%)$ yang mengalami kejadian Arthritis Rheumotoid sedangkan dari 37 lansia dewasa muda yang tidak mengalami kejadian penyakit genetik terdapat $(46,0 \%)$ yang tidak mengalami kejadian Arthritis Rheumotoid. Hasil uji statistik dengan menggunakan uji Chi Square, didapat nilai $p$-value 0,002 yang berarti lebih kecil dari $\alpha(0,05)$ maka Ho ditolak dan $\mathrm{Ha}$ diterima, berarti ada hubungan yang bermakna antara genetik dengan Kejadian Arthritis Rheumotoid.

\section{PEMBAHASAN}

Berdasarkan hasil penelitan diketahui dari 69 responden bahwa sebagian besar lansia dewasa muda berpengetahuan cukup $(71,0 \%)$, hal ini sesuai dengan teori,dimana seseorang memasuki tahap lansia maka akan mengalami beberapa kemampuan intelektual menurun sedangkan kemampuan lainyatidak.hasil uji Chi Square menunjukan nilai $p(0,017)>0,005$. maka Ho di tolak artinya ada hubungan kejadian Arthritis rheumotoid dengan Pengetahuan. Berdasarkan hasil penelitian diketahui dari 69 responden sebagian besar responden berjenis kelamin perempuan $(68,0)$, hal ini sesuai dengan teori, dimana perbandian usia subur wanita berbanding 5:1. hasil uji Chi Square menunjukan nilai $\mathrm{p}(0,031)>0,005$. maka Ho di tolak artinya ada hubungan kejadian Arthritis rheumotoid dengan jenis kelamin. Berdasarkan hasil penelitian diketahui dari 69 responden hampir sebagian responden aktivitas rendah $(85,0 \% \%)$, hal ini sesuai dengan teori, dimana banyak orang berfikir pergerakan tubuh menyebabkan memperburuk sendi. hasil uji Chi Square menunjukan nilai $\mathrm{p}(0,017)>0,005$. maka Ho di tolak artinya ada hubungan kejadian Arthritis rheumotoid dengan Aktivitas. Berdasarkan hasil penelitian diketahui dari 69 responden sebagian besar tidak ada keturunan $82,0 \%$. hal ini sesuai dengan teori, dimana tfaktor genetik hanya berpengaruh pada beberapa jeni arthritis. hasil uji Chi Square 
menunjukan nilai $p(0,05)>0,005$. maka Ho di tolak artinya ada hubungan kejadian Arthritis rheumotoid dengan fakto Genetik.

\section{KESIMPULAN}

Berdasarkan hasil penelitian tentang faktor-faktor yang berhubungan dengan kejadian dengan lansia dewasa muda di Puskesmas Ratu Agung Tahun 2016.makaa dapat di tarik kesimpuln sebagai berikut:

1. Sebagian besar dari responden berpengetahuan cukup beresiko dengan kejadian Arthritis Rheumotoid

2. Sebagian Besar dari responden berjenis kelamin perempuan beresiko dengan kejadian Arthritis Rheumotoid

3. Hampir sebagian dari responden beraktivitas sedang beresiko dengan kejadian Arthritis Rheumotoid

4. Hampir sebagian dari responden faktor genetik beresiko dengan kejadian Arthritis Rheumotoid.

\section{SARAN}

1. Bagi Puskesmas Ratu Agung

Agar Puskesmas Ratu Agung dapat memberikan fasilitas berupa sumber informasi dan memotivasi Pada lanjut usia dewasa muda.

2. Bagi Peneliti Selanjutnya

Dari hasil penelitian ini, diketahui bahwa pengetahuan lanjut usia dewasa muda tentang penyakit Arthritis Rheumotoid sebagian besar masih kurang, oleh karena itu peneliti menyarankan bagi peneliti selanjutnya dapat melakukan penelitian kepada aspek yang lebih luas lagi.

3. Bagi Instansi pendidikan keperawatan dan ilmu keperawatan.

Meningkatkan peran instansi terkait serta perawat khususnya keperawatan medikal bedah dan keperawatan gerontik dalam pelaksanaan promosi, preventif, dan rehabilitasi khususnya lanjut usia dewasa muda terhadap Arthritis Rheumotoid.

\section{DAFTAR PUSTAKA}

BPS, departemen sosial. 2004.Analisa Deskriptif penyandang Masalah kesejahteraan Sosial 2003. Jakarta :BPS-Departeent Sosial

Brunner \& Suddarth, 2001. Buku Ajar Keperawatan Medikal Bedah.Jakarta:EGC.

Corwin,Elizabeth J.2009. Buku Saku Patofisiologi.Jakarta:EGC.

Depkes RI, 2012.Profil Kesehatan Indonesia tahun 2011.Jakarta : Depkes RIDinkes Kota Bengkulu, 2014. Profil Dinkes Kota Bengkulu 2014.Bengkulu : DepkesKota Bengkulu.

Notoatmodjo, Soekidjo. Promosi Kesehatan dan Ilmu Perilaku.Jakarta :RinekaCipta. 2011Nursalam. Konsepdan Penerapan Metodologi Penelitian Ilmu Keperawatan. Jakarta: Salemba Medika. 2007. 